\title{
Respiratory Pathogens Associated with Intubated Pediatric Patients following
}

\section{Hematopoietic Cell Transplant}

\author{
Running Title: Respiratory Pathogens in Pediatric HCT
}

Shira J. Gertz, MD 1; Jennifer McArthur, DO 2; Deyin D. Hsing, MD 3; Mara E. Nitu, MD 4; Lincoln S. Smith, MD ${ }^{5}$; Ashley Loomis, MD ${ }^{6}$, Julie C. Fitzgerald, MD, PhD ${ }^{7}$; Christine N. Duncan, MD 8; Kris M. Mahadeo, MD, MPH 9; Jerelyn Moffet, NP 10; Mark W. Hall, MD ${ }^{11}$; Emily L. Pinos, CRNP, MSN 12; Ira M. Cheifetz, MD ${ }^{13}$ and Courtney M. Rowan, MD,${ }^{4}$ for the Pediatric Acute Lung Injury and Sepsis Investigators (PALISI) Network

Institutional Affiliations: 1 - Department of Pediatrics, Saint Barnabas Medical Center, Livingston, NJ; 2 - Department of Pediatrics, Division of Critical Care, St. Jude's Children's Research Hospital, Memphis, TN and Department of Pediatrics Division of Critical Care Medicine, Medical College of Wisconsin, Milwaukee, WI; 3- Department of Pediatrics, Division of Critical Care, Weil Cornell Medical College, New York Presbyterian Hospital, New York City, NY; 4 - Department of Pediatrics, Division of Critical Care, Riley Hospital for Children, Indiana University School of Medicine, Indianapolis IN; 5 - Department of Pediatrics, Division of Pediatric Critical Care Medicine, Seattle Children's Hospital, University of Washington, Seattle, WA; 6 - Department of Pediatrics, Division of Critical Care, Masonic Children's Hospital, University of Minnesota, Minneapolis, MN; 7 - Department of Anesthesiology and Critical Care, Division of Critical Care, Children's Hospital of Philadelphia, University of Pennsylvania Perelman School of Medicine, Philadelphia, PA; 8 - Department of Pediatrics, Pediatric Oncology, Dana-Farber Cancer Institute Harvard University, Boston, MA; 9 - Department of Pediatrics, Division of Pediatric Stem Cell Transplant and Cellular Therapy, University of Texas at MD Anderson Cancer Center; 10 - Department of Pediatrics, Division of Blood and Marrow Transplant, Duke Children's Hospital, Duke University, Durham, NC; 11 - Department of Pediatrics, Division of Critical Care, Nationwide Children's Hospital, The Ohio State University, Columbus, $\mathrm{OH} ; 12$ - Pennsylvania State University College of Medicine, Penn State Hershey Children's Hospital; 13 - Department of Pediatrics, Division of Critical Care, Duke Children's Hospital, Duke University, Durham, NC

The study was performed at the following institutions: Riley Hospital for Children at Indiana University School of Medicine; Joseph M Sanzari Children's Hospital at Hackensack University Medical Center; Medical College of Wisconsin, Children's Hospital of Wisconsin; Children's Hospital of Philadelphia, University of Pennsylvania Perelman School of Medicine; University of Minnesota, Masonic Children's Hospital; Weil Cornell Medical College, New York Presbyterian Hospital; Dana-Farber Cancer Institute; Children's Hospital of Los Angeles; University of Washington and Seattle Children's Hospital; Duke Children's Hospital; Nationwide Children's Hospital; Penn State Children's Hospital

Corresponding Author: Courtney Rowan, MD, MScr 705 Riley Hospital Dr.

Phase 2, 4900

Indianapolis, IN 46202

Office: 317-944-7065

Email: coujohns@iu.edu

This is the author's manuscript of the article published in final edited form as:

Gertz, S. J., McArthur, J., Hsing, D. D., Nitu, M. E., Smith, L. S., Loomis, A., Fitzgerald, J. C., Duncan, C. N., Mahadeo, K. M., Moffet, J., Hall, M. W., Pinos, E. L., Cheifetz, I. M., \& Rowan, C. M. (2020). Respiratory pathogens associated with intubated pediatric patients following hematopoietic cell transplant. Transplant Infectious Disease, 22(4), e13297. https://doi.org/10.1111/tid.13297 


\section{Conflicts of interest statement:}

S.J.G., J.M, D.D.H., M.E.N., L.S.S., A.L., J.C.F., C.N.D., K.M.M., J.M., M.W.H., E.L.P., C.M.R, have no conflicts of interest to disclose

I.M.C. discloses he is a medical advisor for Philips and a contributor for Up-to-Date - neither has any relation to the topic of this manuscript. 


\section{Abstract \\ Background:}

We describe organisms found in the respiratory tracts of a multicenter cohort of pediatric hematopoietic cell transplant $(\mathrm{HCT})$ recipients with respiratory failure.

\section{Methods:}

Twelve centers contributed up to 25 pediatric allogeneic HCT recipients requiring mechanical ventilation for respiratory failure to a retrospective database. Positive respiratory pathogens and method of obtaining sample were recorded. Outcomes were assessed using Mann Whitney $U$ test or Chi squared analysis.

\section{Results:}

Of the 222 patients in the database, ages 1 month to 21 years, $34.6 \%$ had a positive respiratory culture. 105 pathogens were identified in 77 patients; of those $48.6 \%$ were viral, $34.3 \%$ bacterial, $16.2 \%$ fungal and $1 \%$ parasitic. PICU mortality with a respiratory pathogen was $68.8 \%$ compared to $54.9 \%$ for those without a respiratory pathogen $(p=0.045)$. Those with a positive respiratory pathogen had longer PICU length of stay, 20 days (IQR 14.0, 36.8) vs 15 (IQR 6.5, 32.0), $p=0.002$ and a longer course of mechanical ventilation, 17 days (IQR 10, 29.5) vs 8 (3, 17), $p<0.0001$. Method of pathogen identification, type of pathogen, and the presence of multiple pathogens, were not associated with changes in PICU outcomes.

\section{Conclusions:}

In this multi-center retrospective cohort of intubated pediatric post-HCT patients there was high variability in the respiratory pathogens identified. Type of pathogen and method of detection did not affect PICU mortality. The presence of any organism leads to increased PICU mortality, longer PICU stay, and increased duration of mechanical ventilation suggesting that early detection and treatment of pathogens may be beneficial in this population.

Keywords: Hematopoietic stem cell transplantation, pneumonia, respiratory insufficiency, immunocompromised, pediatrics 


\section{Introduction}

Allogeneic hematopoietic cell transplant $(\mathrm{HCT})$ is a potentially curative treatment for children with both malignant and non-malignant diseases. The process of HCT, however, is fraught with complications, and as many as $75 \%$ of pediatric patients undergoing HCT experience pulmonary complications [1]. The presence of respiratory symptoms and/or chest radiographic findings pose a diagnostic dilemma. Differentiating infectious from non-infectious lung injury is vital, especially among patients with graft-versus-host-disease, where management is typically divergent. Once intubated, the mortality rate for this population can be as high as $60 \%$ [2-4] as compared with the $33 \%$ [5] mortality of all children with severe pediatric acute respiratory distress syndrome (PARDS). In the original publication from this dataset, those with a positive respiratory culture had an increased risk of mortality. The presence of any pathogen significantly increased the odds of death, OR $2.2(95 \% \mathrm{Cl}: 1.1,4.3), p=0.03$ [2]. However, specific types of pathogens were not fully explored.

Children post-HCT with lower respiratory tract infections (LTRI) are both a diagnostic and therapeutic challenge. While LTRI in general can be diagnosed with modified Centers for Disease Control criteria that take into account fever, radiographic changes, and at least two characteristic pulmonary symptoms (i.e., dyspnea, rhonchi, sputum, cough and/or rales) [6], the HCT patient is more complex. Conventional chest roentgenography may be normal in $40-56 \%$ $[7,8]$ of patients post HCT and are often non-specific. High resolution computerized tomography (CT) identifies abnormalities in 66-94\% [8,9] of patients though it increases radiation exposure without specificity to judiciously guide antimicrobial selection.

Given the very high risk of infections, with a wide range of possible pathogens in this population, patients are often exposed to excessive and prolonged antibiotic courses. When diagnostic 
testing identifies a pathogen, the specimens are from upper respiratory secretions $(63 \%)$, bronchoalveolar lavage (BAL) (29\%), and open lung biopsy (8\%) [10]. Invasive testing such as BAL and open lung biopsy, usually occurs after empiric broad-spectrum antibiotic therapy has begun. If testing is delayed until antibiotic treatment has failed, the pathogen yield is highly variable, reported between $22-73 \%$ [11-16] and frequently lacking concordance [17,18]. Earlier BAL has been associated with better pathogen yield and decreased mortality [19]. While improvements in diagnostic capabilities are being investigated [20], these newer technologies are not widely available and currently do not function in real-time. Therefore, understanding the common respiratory pathogens in children post-HCT, and their association with mortality, may help guide specific diagnostic investigations and empiric antimicrobial therapy.

The primary goal of this study is to describe the various pathogens found in a multi-center group of children post-HCT with severe respiratory failure requiring invasive mechanical ventilation. We hypothesize that patients with an identified respiratory pathogen (via any detection methodology) have worse PICU outcomes than those without a respiratory pathogen.

\section{Patients and Methods:}

This is a secondary analysis of a retrospective database. After institutional review board approval was obtained at each site, twelve centers contributed up to 25 consecutive allogeneic HCT patients from 2009-2014 who were admitted to the pediatric intensive care unit (PICU) with respiratory failure requiring mechanical ventilation. Respiratory failure was defined as patients needing intubation for critical illness. All patients between the ages of 1 month to 21 years were included, and the database contains 222 patients. Detailed data regarding the methods for this database collection were previously published [2]. Respiratory pathogens were collected via bronchoalveolar lavage, tracheal aspirate, nasopharangeal swab or wash, and lung biopsy and subsequently identified using PCR, direct florescent antigen or cultured. Some 
institutions used quantitative measurements for growth in culture and others used qualitative; any growth was considered positive for this study. As this was a retrospective database each institution had their own microbiology lab that performed their standard at the time.

Study data were collected and managed using a centralized REDCap electronic data capture tool hosted at Indiana University [21]. Results are displayed as medians with interquartile ranges (IQR) and were compared using Mann Whitney $U$ test for continuous variables. Categorical variables are expressed as number with percentages and were compared with ChiSquared analysis or Fisher's Exact test where appropriate. Statistical significance was considered with a $p$ value of $<0.05$. Statistical Package of Social Science (SPSS) for Windows, Version 24 (SPSS Inc., Chicago IL) was used for the analysis.

\section{Results}

Demographics

Eighty patients $(36 \%)$ of the 222 in the database were documented to have a respiratory pathogen (viral, bacterial, fungal, or parasitic). Three patients were excluded as they were documented to have a respiratory pathogen, but were missing detailed respiratory pathogen data. Seventy-seven patients $(34.6 \%)$ with detailed respiratory pathogen data were included in the study and compared with 142 patients from the same database with no documented respiratory pathogen. The percentage of patients intubated for respiratory failure with a positive respiratory pathogen was variable at each institution with a median of $32.7 \%$ per institution (IQR: $27.7 \%, 44.6 \%$ ). Those with a respiratory pathogen were more likely to have had a cord blood transplant, an unrelated donor, and respiratory distress present at PICU admission. There was no difference in age, presence of an underlying malignant diagnosis leading to transplant, or time post-transplant at PICU admission (Table 1). 


\section{Outcomes}

Those with the presence of a respiratory pathogen also had worse PICU outcomes. In addition to increased PICU mortality, they had a longer length of invasive mechanical ventilation, longer length of PICU stay, and increased use of rescue strategies such as high frequency oscillatory ventilation and inhaled nitric oxide (Table 1). Overall, PICU mortality for those with a documented respiratory pathogen was $68.8 \%$ as compared with $54.9 \%$ for those without a pathogen, $(p=0.045)$. While not reaching statistical significance, this difference continued, with a higher mortality at 180 days after PICU stay; $83 \%$ for those with an identified respiratory pathogen compared to $71 \%$ for those without an identified infection $(p=0.070)$. On multivariate analysis, adjusting for age, day post-HCT, malignant diagnosis, use of renal replacement therapy, and use of vasoactive agents, the presence of a respiratory pathogen was still associated with an increased risk of mortality (Table 2)

\section{Pathogens}

Respiratory pathogens were numerous. There were a total of 31 different organisms found in the respiratory tracts of our population. Viral pathogens were the most common, being present in $53.2 \%(n=41)$ of patients, followed by bacteria in $38.9 \%(n=30)$; fungal infection in $23.4 \%$ $(n=18)$, and a parasite in one patient. Of those with a viral pathogen, $56 \%(n=23)$ had just one virus isolated with the remaining 18 having additional pathogens identified along with the virus. The majority $(67 \%, n=20)$ of those with bacteria, had just one bacterial pathogen identified, and $56 \%$ of those with a fungus had just one isolated fungal pathogen identified. The median day post-HCT at the time of intubation was highly variable among types of pathogens, but this did not reach statistical difference [viral= 45 days (IQR: 18-106), bacteria=65 (IQR: 24, 161), and fungal=116 (IQR: 50, 182), $p=0.09]$. 
There was no difference in mortality for any class of infection or for the presence of multiple pathogens. Mortality rates were as follows: bacteria $60.0 \%$, viruses $75.6 \%$, and fungi $77.8 \%$. The one patient with a parasite (who also had a virus) survived. The specific pathogens identified were diverse and a mixture of both common pathogens and opportunistic organisms. A list of all the specific pathogens and number of infected patients can be found in Table 3 . Adenovirus was the most common pathogen isolated in this cohort, infecting 17 children with only 2 surviving to PICU discharge. Multiple respiratory pathogens were identified in $31.2 \%$ $(n=24)$ of patients and mortality with multiple pathogens was $70.8 \%$. A total of eight patients were diagnosed with a candidal respiratory infection, and none survived to PICU discharge.

The combination of pathogens varied, including multiple viruses, bacteria, fungi, or combinations of different types of pathogens. The different combinations of multiple pathogens, the methods by which they were identified, and survival are detailed in Table 4. All patients who were co-infected with a fungal pathogen died.

\section{Method of pathogen identification}

Of the 77 patients with detailed respiratory pathogen data, $50.6 \%(n=39)$ of organisms were found with a bronchoalveolar lavage $(B A L), 40.3 \%(n=31)$ were found with a tracheal aspirate, $7.8 \%(n=6)$ were found with a nasopharyngeal swab/wash, and 1 was found with a lung biopsy. Hypothesizing that pathogens identified by tracheal aspirates may be more likely to represent colonization rather than true infection, an exploratory subanalysis was conducted to compare markers of severity of illness for those with a pathogen identified by a tracheal aspirate compared to those with a pathogen identified by BAL or lung biopsy. The method of pathogen identification was not associated with PICU mortality $(p=0.76)$, use of high frequency oscillatory ventilation $(p=0.94)$, use of inhaled nitric oxide $(p=0.30)$, vasoactive use $(p=0.12)$, length of PICU stay $(p=0.75)$, or length of mechanical ventilation $(p=0.20)$ (Table 5). While not reaching 
statistical significance, there seem to be a trend with high renal replacement therapy use in those identified by a tracheal aspirate $(p=0.07$, Table 5) Under the hypothesis that bacterial pathogens would be the most likely to represent colonization, a further exploratory analysis of those with an identified bacterial pathogen was undertaken. Once again categorizing those with pathogens identified by tracheal aspirate compared those identified by BAL/lung biopsy, there was no difference in PICU mortality $(64 \%$ vs $58 \%, p=0.99), 180$ day mortality $(72 \%$ vs $74 \%$, $p=0.99$ ), length of PICU stay or length of mechanical ventilation. Patients with positive pathogens from a tracheal aspirate were also compared to those who did not have a pathogen identified. While not reaching statistical significance, those with a pathogen from a tracheal aspirate had a trend toward higher PICU mortality than those without a pathogen identified $(71 \%$ vs $55 \%, p=0.10)$. They also had a longer length of PICU stay $(p=0.01)$ and a longer length of mechanical ventilation $(p<0.001)$ than those without a respiratory pathogen identified. CT scan of the lungs was done in $57.1 \%(n=44)$ of patients; $95 \%(41 / 44)$ had findings consistent with or concerning for infection. Only $39 \%(n=56)$ of those without a documented pathogen had a CT scan of the chest. Of these 56 patients, $50 \%(n=28)$ had a CT read concerning for an infectious process.

\section{Discussion}

In this multicenter retrospective cohort of intubated pediatric post-HCT patients, over $35 \%$ had the documented presence of a respiratory pathogen. Characterization suggests the presence of diverse pathogens including both common and opportunistic. Co-detection of more than one respiratory pathogen in this cohort was also common. While having an identified pathogen was associated with a higher mortality, there was not a statistical difference in the mortality rate among types of pathogens. Furthermore, the method of pathogen identification did not seem to be associated with PICU outcomes. Overall, those with a documented respiratory pathogen, 
identified by any method, had poor outcomes, suggesting the presence of true infection and necessitating the question of how to best change practice to improve outcomes.

Early diagnostic techniques may have the ability to improve outcomes. Quick, targeted antibiotic therapy may prevent worsening respiratory failure and subsequent progressive multiorgan dysfunction. It is interesting to note, that in our dataset, almost all patients with an identified pathogen had evidence of concern for infection on chest CT, compared to only half of the patients without an identified pathogen. This potentially adds value to obtaining a chest CT when considering an infectious versus noninfectious process; however, it is obviously not useful in helping to choose targeted antimicrobial therapy. Sampling of the respiratory tract for pathogen testing is the only method able to provide this information. Using BAL for diagnosis becomes a further challenge in the HCT recipient due to the concerns for the risk of bronchoscopy potentiating respiratory failure and causing clinical decompensation [22]. Early bronchoscopy, particularly before prolonged antibiotic exposure, can improve the diagnostic output and accuracy of a BAL respiratory culture and testing [19]. While there are clearly risks to bronchoscopy, there is a suggestion that early bronchoscopy can decrease the risk of complications [19]. The risks and benefits must be carefully weighed for each patient, keeping in mind the excessive mortality rate noted with respiratory infections.

Other means of diagnostic investigation can include nasopharyngeal washes or swabs for viral panel testing via PCR. These panels are now pervasive and test for an ever increasing number of viruses with quick [23] (hours), accurate [24] results, but at the time of data collection for this study were not as widely available at all centers and, thus, less frequently used. Tracheal aspirates can be obtained from endotracheal tubes with minimal risk [22]. The ability of tracheal aspirates to identify true infection has been questioned, with data to suggest that it is not able to distinguish true infection from colonization in a pediatric cohort [25]. In this dataset, patients 
with pathogens identified from a tracheal aspirate had similar or worse outcomes as compared to those with a pathogen from a BAL, or those patients without an identified respiratory pathogen. This suggests, that perhaps in our immunocompromised cohort, tracheal aspirate cultures may represent true infection; clearly prospective studies are needed to better answer this question. With the current data from this multicenter cohort, bedside clinicians should be hesitant to explain the results of a tracheal aspirate as colonization and stop antibiotic therapy in the absence of another reliable etiology of respiratory failure.

Blood testing includes viral antibody and PCR tests; however, as therapeutic options for viruses are limited, identification of a specific type may not alter the therapeutic course. However, blood tests may be especially useful in fungal infections. Despite the lack of statistical significance, there are some concerns that those with a fungal pathogen fare worse, particularly when there is more than one pathogen identified. Most notably, there was a $100 \%$ mortality with a candida pneumonia. Early identification of candida, and treatment with appropriate and aggressive antifungal therapy may be important to improve survival. In addition to galactomannan testing for aspergilloses and 1,3 $\beta \mathrm{D}$ glucan testing for evidence of a fungal pathogen, there are newer fungal blood tests specific to candida infections [26]. With the high rate of fungal-associated, and in particular candida-related mortality, found in this cohort and previously reported [27], fungal prophylaxis strategies and early candida coverage may need to be considered in patients at high risk for invasive fungal disease.

As the clinician considers diagnostic work-up and antimicrobial therapy, it is important to remember that this cohort had a high rate of multiple-pathogen infections. Almost a third of those infected had two or more pathogens. This suggests that identification of a specific pathogen does not preclude the presence of an additional infection. If the patient is not improving, further diagnostic work-up may be indicated. The possibility of co-infections must 
also be thoughtfully considered when starting or adjusting antimicrobial therapy. As the mortality for this patient population is the highest of all intubated patients in the PICU with respiratory failure [2-4], early identification of pathogens by any means, and prompt focused antimicrobial treatment without forgetting that multiple pathogens are frequently present, offers these patients the best opportunity at survival.

One limitation of this study is the lack of precise timing of the identified infection during the course of the respiratory failure. Additionally, not all patients had respiratory sampling and the database is lacking details on those patients who had a negative diagnostic work-up. Finally, another limitation is the lack of information on the use of antibiotic therapy. While these are clear limitations to this study, the large pediatric sample size and number of institutions across geographic areas of the county make the results highly generalizable.

\section{Conclusion:}

Respiratory infections were found in over one third of this multi-center lcohort of intubated pediatric post-HCT patients. There was a high variability in respiratory pathogens identified. Infections due to multiple pathogens were common and should be considered in clinical practice. While there is no association with a specific type of infection and PICU mortality, having a positive respiratory infection leads to higher PICU mortality, longer length of PICU stay, and increased duration of mechanical ventilation. The means of identification of the pathogen was not associated with outcome. Understanding which pathogens affect the respiratory tract and their associated mortality, may help guide selection of antimicrobial agents until a specific diagnosis can be obtained. 


\section{References:}

1. Kaya Z, Weiner DJ, Yilmaz D, et al: Lung function, pulmonary complications, and mortality after allogeneic blood and marrow transplantation in children. Biol Blood Marrow Transplant 2009;15:817-826

2. Rowan CM, Gertz SJ, Mcarthur J, et al. Pediatric Critical Care Medicine Invasive Mechanical Ventilation and Mortality in Pediatric Hematopoietic Stem Cell Transplantation: A Multicenter Study. Pediatr Crit Care Med 2016;17:294-302.

3. Chima RS, Daniels RC, Kim MO, et al. Improved outcomes for stem cell transplant recipients requiring pediatric intensive care. Pediatr Crit Care Med 2012;13:e336-42.

4. Duncan CN, Lehmann LE, Cheifetz IM, et al. Clinical outcomes of children receiving intensive cardiopulmonary support during hematopoietic stem cell transplant. Pediatr Crit Care Med 2013;14:261-267.

5. Khemani RG, Smith L, Lopez-Fernandez YM, et al. Paediatric acute respiratory distress syndrome incidence and epidemiology (PARDIE): an international, observational study. Lancet Respir Med 2019;7:115-128.

6. Zinter MS, Levy ER, Gertz SJ, Care C, Sanzari JM. A review of pathogens causing lower respiratory tract infection in the pediatric hematopoietic stem cell transplant recipient. $J$ Pediatr Intensive Care 2014;3:115-132.

7. Barloon TJ, Galvin JR, Mori M, Stanford W, Gingrich RD. High-resolution ultrafast chest CT in the clinical management of febrile bone marrow transplant patients with normal or nonspecific chest roentgenograms. Chest 1991;99:928-933.

8. Schueller G, Matzek W, Kalhs P, Schaefer-Prokop C. Pulmonary infections in the late period after allogeneic bone marrow transplantation: chest radiography versus computed tomography. Eur J Radiol 2005;53:489-494.

9. Escuissato DL, Gasparetto EL, Marchiori E, et al. Pulmonary Infections After Bone Marrow Transplantation: High-Resolution CT Findings in 111 Patients. Am J Roentgenol 
2005;185:608-615.

10. Aguilar-Guisado M, Jiménez-Jambrina M, Espigado I, et al. Pneumonia in allogeneic stem cell transplantation recipients: a multicenter prospective study. Clin Transplant 2011;25:E629-E638.

11. Forslöw U, Remberger M, Nordlander A, Mattsson J. The clinical importance of bronchoalveolar lavage in allogeneic SCT patients with pneumonia. Bone Marrow Transplant 2010;45:945-950.

12. Eikenberry M, Bartakova H, Defor $\mathrm{T}$, et al. Natural history of pulmonary complications in children after bone marrow transplantation. Biol Blood Marrow Transplant 2005;11:5664.

13. Gilbert CR, Lerner A, Baram M, Awsare BK. Utilidad de la broncoscopia flexible en la evaluación de infiltrados pulmonares en la población con trasplante de células madre hemopoyéticas: experiencia de 14años en un solo centro. Arch Bronconeumol 2013;49:189-195.

14. Qualter E, Satwani P, Ricci A, et al. A Comparison of Bronchoalveolar Lavage versus Lung Biopsy in Pediatric Recipients after Stem Cell Transplantation. Biol Blood Marrow Transplant 2014;20:1229-1237.

15. Armenian SH, Hoffman JA, Butturini AM, Kapoor N, Mascarenhas L. Invasive diagnostic procedures for pulmonary infiltrates in pediatric hematopoietic stem cell transplant recipients. Pediatr Transplant 2007;11:736-742.

16. Dunn JC, West KW, Rescorla FJ, et al. The utility of lung biopsy in recipients of stem cell transplantation. J Pediatr Surg 2001;36:1302-1303.

17. Ben-Ari J, Yaniv I, Nahum E, Stein J, Samra Z, Schonfeld T. Yield of bronchoalveolar lavage in ventilated and non-ventilated children after bone marrow transplantation. Bone Marrow Transplant 2001;27:191-194.

18. Snyder CL, Ramsay NK, McGlave PB, Ferrell KL, Leonard AS. Diagnostic open-lung 
biopsy after bone marrow transplantation. J Pediatr Surg 1990;25:871-876;

19. Shannon VR, Andersson BS, Lei X, Champlin RE, Kontoyiannis DP. Utility of early versus late fiberoptic bronchoscopy in the evaluation of new pulmonary infiltrates following hematopoietic stem cell transplantation. Bone Marrow Transplant 2010;45:647655.

20. Zinter MS, Dvorak CC, Mayday MY, et al. Pulmonary Metagenomic Sequencing Suggests Missed Infections in Immunocompromised Children. Clin Infect Dis 2019;68:1847-1855.

21. Harris PA, Taylor R, Thielke R, Payne J, Gonzalez N, Conde JG. Research electronic data capture (REDCap)--a metadata-driven methodology and workflow process for providing translational research informatics support. J Biomed Inform 2009;42:377-381.

22. Azoulay E, Mokart D, Rabbat A, et al. Diagnostic bronchoscopy in hematology and oncology patients with acute respiratory failure: Prospective multicenter data. Crit Care Med 2008;36:100-107.

23. Rogers BB, Shankar $\mathrm{P}$, Jerris $\mathrm{RC}$, et al. Impact of a rapid respiratory panel test on patient outcomes. Arch Pathol Lab Med 2015;139:636-641.

24. van Kraaij MGJ, van Elden LJR, van Loon AM, et al. Frequent Detection of Respiratory Viruses in Adult Recipients of Stem Cell Transplants with the Use of Real-Time Polymerase Chain Reaction, Compared with Viral Culture. Clin Infect Dis 2005;40:662669.

25. Willson DF, Conaway M, Kelly R, Hendley JO. The lack of specificity of tracheal aspirates in the diagnosis of pulmonary infection in intubated children. Pediatr Crit Care Med 2014;15:299-305.

26. Clancy CJ, Pappas PG, Vazquez J, et al. Detecting Infections Rapidly and Easily for Candidemia Trial, Part 2 (DIRECT2): A Prospective, Multicenter Study of the T2Candida Panel. Clin Infect Dis 2018;66:1678-1686. 
27. Wingard JR, Merz WB, Rinaldi MG et al. Increase in Candida krusei Infection among Patients with Bone Marrow Transplantation and Neutropenia Treated Prophylactically with Fluconazole. N Engl J Med 1991;325:1274-1277. 
Table 1: Demographics stratified by the presence of an identified respiratory pathogen

\begin{tabular}{|c|c|c|c|}
\hline Demographic & $\begin{array}{l}\text { Respiratory } \\
\text { Pathogen } \\
\mathrm{N}=77\end{array}$ & $\begin{array}{l}\text { No Respiratory } \\
\text { Pathogen } \\
\mathrm{N}=142\end{array}$ & $\mathbf{p}$ \\
\hline Age & $7.6(2.0,15.1)$ & $9.9(2.3,16.2)$ & 0.24 \\
\hline Female & $31(40 \%)$ & $64(45 \%)$ & 0.47 \\
\hline $\begin{array}{l}\text { Source of Transplant } \\
\text { Bone Marrow } \\
\text { Cord Blood } \\
\text { Peripheral Blood }\end{array}$ & $\begin{array}{l}27(35 \%) \\
39(51 \%) \\
11(14 \%)\end{array}$ & $\begin{array}{l}74(52 \%) \\
48(34 \%) \\
20(14 \%)\end{array}$ & 0.04 \\
\hline Related Donor & $9(12 \%)$ & $37(26 \%)$ & 0.01 \\
\hline Malignant diagnosis leading to transplant & $39(51 \%)$ & $67(47 \%)$ & 0.62 \\
\hline Day post- $\mathrm{HCT}^{\dagger}$ at $\mathrm{PICU}{ }^{\ddagger}$ admit & $48.0(13.0,122.0)$ & $36.5(14.8,91.3)$ & 0.34 \\
\hline Respiratory distress at PICU admission & $71(92 \%)$ & $103(73 \%)$ & 0.001 \\
\hline PICU $\ddagger$ Mortality & $53(69 \%)$ & $78(55 \%)$ & 0.045 \\
\hline Mortality at 180 days post $\mathrm{PICU} \ddagger$ stay & $64(83 \%)$ & $101(71 \%)$ & 0.070 \\
\hline Length of PICU stay & $20.0(14.0,36.0)$ & $15.0(6.0,32.5)$ & 0.003 \\
\hline $\begin{array}{l}\text { Length of invasive mechanical } \\
\text { ventilation }\end{array}$ & $17.0(10.0,28.0)$ & $8.0(3.0,17.0)$ & $<0.001$ \\
\hline $\begin{array}{l}\text { Use of high frequency oscillatory } \\
\text { ventilation }\end{array}$ & $37(48 \%)$ & $46(32 \%)$ & 0.02 \\
\hline Use of inhaled nitric oxide & $27(35 \%)$ & $29(20 \%)$ & 0.02 \\
\hline Use of renal replacement therapy & $33(43)$ & $45(32 \%)$ & 0.09 \\
\hline Use of vasoactive agents & $54(70 \%)$ & $108(76 \%)$ & 0.34 \\
\hline
\end{tabular}

Data are presented as medians with (interquartile ranges) for continuous variables and were compared

with a Mann Whitney $U$ test. For categorical variables, data are presented as counts with (percentage)

and were compared with a chi squared or Fisher's Exact test where appropriate. Percentages are

rounded to the nearest whole number. $\dagger-\mathrm{HCT}=$ hematopoietic cell transplant, $\ddagger-\mathrm{PICU}=$ pediatric

intensive care unit 
Table 2: Multivariate analysis for PICU mortality

\begin{tabular}{|l|l|l|}
\hline & Odds Ratio $(95 \%$ confidence interval) & $\mathrm{p}$ \\
\hline Presence of a respiratory pathogen & $2.2(95 \% \mathrm{Cl}: 1.2,4.1)$ & 0.014 \\
\hline Use of vasoactive agents & $3.1(95 \% \mathrm{Cl}: 4.6,5.9)$ & 0.001 \\
\hline
\end{tabular}

Using backward stepwise conditional multivariate regression, the initial model include age,

malignant diagnosis, day post hematopoietic cell transplantation, use of renal replacement

therapy, use of vasoactive agents, and the presence of an identified respiratory pathogen. Only

respiratory pathogen and the use of vasoactive agents remained significant in the final model.

Vasoactive agents were considered to be continuous infusions of epinephrine, norepinephrine, vasopressin, dopamine, dobutamine or milrinone. 
Table 3: List of pathogens identified from respiratory specimens in a cohort of intubated pediatric HCT patients

\begin{tabular}{|c|c|c|c|c|}
\hline Pathogen & $\underline{\mathbf{n}}$ & $\frac{\%}{\text { mortality }}$ & $\begin{array}{l}\% \text { of those with } \\
\text { a pathogen } \\
n=77\end{array}$ & $\begin{array}{l}\% \text { all intubated } \\
\text { patients } \\
n=219\end{array}$ \\
\hline \multicolumn{5}{|l|}{ Bacteria } \\
\hline Coagulase negative staphylococcus & 9 & 66.7 & 11.7 & 4.1 \\
\hline Enterococcus & 7 & 28.7 & 9.1 & 3.2 \\
\hline Pseudomonas aeruginosa & 4 & 75.0 & 5.2 & 1.8 \\
\hline Stenotrophomonas & 3 & 100.0 & 3.9 & 1.4 \\
\hline Staphylococcus aureus & 3 & 0.0 & 3.9 & 1.4 \\
\hline Legionella & 2 & 50.0 & 2.6 & 0.9 \\
\hline Enterobacter & 2 & 100.0 & 2.6 & 0.9 \\
\hline Unidentified gram positive cocci & 2 & 100.0 & 2.6 & 0.9 \\
\hline Leuconostoc & 1 & 0.0 & 1.3 & 0.5 \\
\hline Klebsiella & 1 & 100.0 & 1.3 & 0.5 \\
\hline Acinetobacter & 1 & 100.0 & 1.3 & 0.5 \\
\hline Diptheroids & 1 & 0.0 & 1.3 & 0.5 \\
\hline \multicolumn{5}{|l|}{ Viri } \\
\hline Adenovirus & 17 & 88.2 & 22.1 & 7.8 \\
\hline Cytomegalovirus & 10 & 70.0 & 13.0 & 4.6 \\
\hline Rhinovirus/Enterovirus & 8 & 50.0 & 10.4 & 3.7 \\
\hline Respiratory syncytial virus & 6 & 66.7 & 7.8 & 2.7 \\
\hline Parainfluenza & 3 & 66.7 & 3.9 & 1.4 \\
\hline Human metapneumovirus & 3 & 66.7 & 3.9 & 1.4 \\
\hline Human herpesvirus 6 & 2 & 100.0 & 2.6 & 0.9 \\
\hline Herpes simplex virus & 1 & 100.0 & 1.3 & 0.5 \\
\hline Influenza virus & 1 & 0.0 & 1.3 & 0.5 \\
\hline \multicolumn{5}{|l|}{ Fungi } \\
\hline Aspergillus & 5 & 60.0 & 6.5 & 2.3 \\
\hline Candida Albicans & 3 & 100.0 & 3.9 & 1.4 \\
\hline Candida Glabrata & 2 & 100.0 & 2.6 & 0.9 \\
\hline Candida Parapsilosis & 2 & 100.0 & 2.6 & 0.9 \\
\hline Pneumocyctis jirovecii & 1 & 100.0 & 1.3 & 0.5 \\
\hline Cryptococcus & 1 & 0.0 & 1.3 & 0.5 \\
\hline Candida other & 1 & 100.0 & 1.3 & 0.5 \\
\hline Fusarium & 1 & 0.0 & 1.3 & 0.5 \\
\hline Scedosporium prolificans & 1 & 100.0 & 1.3 & 0.5 \\
\hline \multicolumn{5}{|l|}{ Parasite } \\
\hline Toxoplasma & 1 & 0.0 & 1.3 & 0.5 \\
\hline
\end{tabular}

Infections are categorized by type of infection and then listed in descending order by rate of occurrence.

As some patients had more than 1 type of infections, percentages will exceed $100 \%$. Mortality is

expressed as a percentage of those who died with that specific infection. Details of multi-pathogen

infection combinations are detailed in Table 4. 
Table 4: Various combinations of pathogens, means of identification, and survival

\begin{tabular}{|c|c|c|}
\hline Pathogen combination & Means of identification & Survival \\
\hline \multicolumn{3}{|l|}{ Multiple Bacteria } \\
\hline Klebsiella and Stenotrophomonas & $\mathrm{BAL}^{\dagger}$ & No \\
\hline Stenotrophomonas and Coagulase Negative Staphylococci & $\mathrm{TA}^{\ddagger}$ & No \\
\hline Coagulase Negative Staphylococci and Group D Enterococcus & TA & Yes \\
\hline \multicolumn{3}{|l|}{ Multiple Virus } \\
\hline Parainfluenza, Influenza, and Rhinovirus & Nasal§ & Yes \\
\hline Respiratory Syncytial Virus and Human Metapneumovirus & Nasal & No \\
\hline Human Metapneumovirus and Cytomegalovirus & $\mathrm{BAL}$ & Yes \\
\hline Adenovirus and Human Herpesvirus 6 & $\mathrm{BAL}$ & No \\
\hline Respiratory Syncytial Virus and Cytomegalovirus & $\mathrm{BAL}$ & Yes \\
\hline Adenovirus and Cytomegalovirus & Nasal & No \\
\hline Cytomegalovirus and Rhinovirus & TA & No \\
\hline \multicolumn{3}{|l|}{ Multiple Fungi } \\
\hline Candida Albicans and Geotrichum Capitatum & TA & No \\
\hline \multicolumn{3}{|l|}{ Bacteria and Virus } \\
\hline Pseudomonas and Adenovirus & TA & No \\
\hline Pseudomonas, Adenovirus, and Rhinovirus & $\mathrm{BAL}$ & No \\
\hline Methicillin-resistant Staphylococcus Aureus, Enterococcus, and Adenovirus & TA & Yes \\
\hline $\begin{array}{l}\text { Vancomycin-resistant Enterococci, Group D Enterococcus, Coagulase Negative Staphylococci, } \\
\text { and Respiratory Syncytial Virus }\end{array}$ & TA and Nasal & Yes \\
\hline Acinetobacter and Adenovirus & TA & No \\
\hline \multicolumn{3}{|l|}{ Bacteria and Fungus } \\
\hline Coagulase Negative Staphylococci, Vancomycin-resistant Enterococci, and Candida Parapsilosis, & TA & No \\
\hline Rare Gram Positive Cocci and Candida Albicans & TA & No \\
\hline \multicolumn{3}{|l|}{ Virus and Fungus } \\
\hline Adenovirus and Pneumocystis Jirovecii & $\mathrm{BAL}$ & No \\
\hline Cytomegalovirus and Candida Parapsilosis & TA and BAL & No \\
\hline Cytomegalovirus and Aspergillus & $\mathrm{BAL}$ & No \\
\hline Adenovirus, Herpes Simplex Virus, and Candida Glabrata, & BAL & No \\
\hline Rhinovirus and Candida Glabrata & $\mathrm{BAL}$ & No \\
\hline \multicolumn{3}{|l|}{ Virus and Parasite } \\
\hline Cytomegalovirus and Toxoplasma & $\mathrm{BAL}$ & Yes \\
\hline
\end{tabular}


Each description represents a single patient multi-pathogen combination. †- BAL = Bronchoalveolar lavage, $\ddagger-\mathrm{TA}=\mathrm{Tracheal}$ aspirate, $\S-\mathrm{Nasal}$

= Detected from Nasal swab/wash/aspirate sample 
Table 5: PICU outcomes compared by method of pathogen identification

\begin{tabular}{|l|l|l|l|}
\hline & $\begin{array}{l}\text { Tracheal aspirate } \\
\mathbf{n = 3 1}\end{array}$ & $\begin{array}{l}\text { BAL/lung biopsy } \\
\mathbf{n = 4 0}\end{array}$ & $\mathbf{p}$ \\
\hline PICU Mortality & $22(71 \%)$ & $27(68 \%)$ & 0.75 \\
\hline Mortality at 180 days post PICU stay & $26(84 \%)$ & $33(83 \%)$ & 0.99 \\
\hline Length of PICU stay & $26.0(14.5,39.5)$ & $18.5(13.8,33.5)$ & 0.75 \\
\hline Length of invasive mechanical ventilation & $20.0(11.5,30.5)$ & $16.5(8.0,22.0)$ & 0.20 \\
\hline High frequency oscillatory ventilation & $15(48 \%$ & $19(48 \%)$ & 0.94 \\
\hline Use of inhaled nitric oxide & $13(42 \%)$ & $12(30 \%)$ & 0.30 \\
\hline Use of renal replacement therapy & $17(57 \%)$ & $14(35 \%)$ & 0.07 \\
\hline Use of vasoactives & $26(84 \%)$ & $27(68 \%)$ & 0.12 \\
\hline
\end{tabular}

Data are presented as medians with (interquartile ranges) for continuous variables and were compared

with a Mann Whitney $U$ test. For categorical variables, data are presented as counts with (percentage)

and were compared with a chi squared or Fisher's Exact test where appropriate. Percentages are

rounded to the nearest whole number. $\uparrow-P I C U=$ pediatric intensive care unit 